\title{
Beitrag zur Aetiologie und Prophylaxe der sympathischen 0phthalmie.
}

\author{
Von
}

\author{
H. Schmidt-Rimpler, \\ Professor in Göttingen.
}

Hierzu Taf. X, Fig. 1-2.

Die Ansichten darüker, wie eine sympathische Ophthalmie zu Stande kommt, gehen trotz der in letzter Zeit so vielfältig angestellten experimentellen und klinischen Untersuchungen noch weit auseinander. Ebenso werden die einzelnen operativen Methoden, welche die Verhütung jener Affection zum Zweck haben, betreffs ihrer Wirksamkeit und Indication von den in der Praxis stehenden AugenAerzten sehr verschiedenartig beurtheilt. Es dürfte daher die Mittheilung und Besprechung nachfolgender Beobachtungen, welche, wie ich meine, etwas zur Klärung beitragen können, nicht ungelegen kommen.

1. Neurectomia optico-ciliaris. Sympathische Ophthalmie nach 11/2 Jahren. Nachweis normaler Nervenfasern im Ciliarkörper des enucleirten Stumpfes.

Dem Schlosser Fritz B., 21 Jahre alt, flog am 21. Mai 1887 ein grosses Stück Holz gegen das linke Auge. Es zeigte sich, wie mir Herr College May w eg (Hagen) - dem ich hier nochmals für seine freundliche Unterstittzung meineni Dank aus: spreche - mittheilt, an der äusseren Seite des Bulbus eine grosse Lappenwunde, deren innerer Schenkel annähernd senk- 
recht am äusseren Hornhantrande, zum Theil noch in der Hornhant selbst, verlief, während der untere, in einem Winkel nach oben aussen abgehende, äussere Schenkel mehr nach dem Aequator $z u$ in der Sclera lag. In der Nähe des Corpus ciliare war die Sclera vollständig perforirt und klaffend. Hier wurde eine Naht angelegt and das Auge unter antiseptischen Vorkehrungen mit einem Druckverbande gesehlossen. Nachdem die Heilung anfänglich ohne entzündliche Erscheinungen verlaufen war (am 5. Juní $\mathrm{S}=1 / 10$ ), trat am 21. Juni vorübergehend erhebliche Verschlechterung ein; auch wurden dicke Glaskörpertrübungen constatirt. Am 30. Juni konnte Patient, da nach Blutentziehung Besserung erfolgt war, geheilt entlassen werden $(S<1 / 10)$.

Im August stellte sich der Verletzte Herrn Collegen Mayweg von Neuem ror, weil das Auge sich wieder geröthet hatte: es handelte sich um beginnende Phthisis. Da der Bulbus auch auf Druck etwas schmerzhaft war, wurde die Enucleation angerathen. Patient wollte bierauf nicht eingehen und entzog sich der Behandlung. Am 19. October 1887 erschien er dann in der Marburger Augenklinik. Es bestand starke pericorneale Injection, die Cornea war verkleinert (horizontaler Durchmesser 6, verticaler $8 \mathrm{~mm}$ ). Vom äusseren Hornhautrande zieht sich nach hinten hin eine weisse, ca. $5 / 4 \mathrm{~cm}$ lange, tief eingezogene Scleralnarbe; vordere Kammer fast vollständig aufgehoben; Iris verfärbt, hintere Synechien; aus der Pupille reflectirt beim $O p h-$ thalmoscopiren nur wenig grauröthliches Licht, Durchleuchtung unmöglich. Hypotonie; an den oberen Partien des verkleinerten Auges Druckempfindlichkeit. Patient siebt Finger in $30 \mathrm{~cm}$, Projection nur nach aussen und unten sicher.

Das rechte Auge hat im unteren-äusseren Quadranten der Hornhaut einen ziemlich durchscheinenden, grauen Fleck; es ist vollkommen entzündungsfrei und normal. H 0,$5 ; \mathrm{S} 6 / 8$. Unter Anwendung von subcutanen Sublimat-Injectionen, Atropin etc. geht die Druckempfindlichkeit links zurück, aber die pericorneale Injection und der Reizzustand bleibt. Ich schlug daher dem Patienten, der sich vor der Herausnahme des Auges schente, die Neurectomia optieo-ciliaris vor.

Dieselbe wurde am 10. November nach Tenotomie des R. internus so ausgeführt, dass nach Umdrehung des Auges ein bei der Opticus-Durchschneidung stehen gelassenes, $11_{2}^{1 / 2} \mathrm{~cm}$ langes Stück des Nerven dicht am Bulbus abgeschnitten wurde. Gleichzeitig wird die ganze Umgebung zur vollständigen Tren- 
Beitrag z. Aetiologie u. Prophylaxe d. sympathischen Ophthalmie. 201

nung der Ciliarnerven mit der Scheere abrasirt. Nach der Reposition des Auges wurde der Internus wieder angenäht. Die Heilung verlief ohne Zwischenfall. Am 24. November konnte Patient entlassen werden. Stellung und Beweglichkeit des neurectomirten Auges waren durchaus gat. Die Injection des Bulbus ist nach innen ziemlich beträchtlich. Während der centrale Theil der Hornhaut bei Nadel-Berührung sich als unempfindlich $e^{2} w e i s t$, ist an einzelnen Stellen der Peripherie die Sensibilität erhalten. Das rechte Auge vollkommen intact.

Ueber anderthalb Jahre später (19. August 1889) kam Patient wieder in die Augenklinik des Herrn Collegen Mayweg und zwar jetzt mit einer acuten Affection des bisher gesunden rechten Auges. "Es zeigt sich eine starke pericorneale Injection, Trübung des Kammerwassers, Verfärbung der Iris, hintere Synechien etc. Der Augenhintergrund ist nicht deutlich zu erkennen. $\mathrm{H} 2,0 ; \mathrm{S} 1 / 10$. Der linke Bulbus ist klein, phthisisch, auf Druck etwas empfindlich. In der Annahme, dass in Marburg die Neurectomia optico-ciliaris gemacht sei, wurde, trotzdem der linke Bulbus etwas druckempfindlich war, und auch die Cornealnerven wieder functionirten, doch die Diagnose auf ,genuine Irido-Cyclitis“ gestellt, und der Patient einer energischen Schmier- und Schwitzcur unterworfen. Ausserdem wurde er mit Atropin-Einträufelungen und Jodkali behandelt. Es schien anch Anfangs ein Nachlass der Reizerscheinungen einzutreten. Das Sehvermögen wurde vorübergehend besser. Doch dauerte es nicht lange, so traten die früheren Erscheinungen mit noch grösserer Intensität und grösserer Hartnäckigkeit wieder auf. Da alle Mittel fehlschlugen, so unterlag es keinem Zweifel mehr, dass diese Entzündung ron dem linken phthisischen Bubus herrühre. Hierfür sprach auch noch der Umstand, dass jeder, auch der leiseste Druck auf den letzteren, sofort eine stärkere Injection des anderen Auges zur Folge hatte. Da aus diesen Gründen eine sympathische Affection angenommen werden musste, so wurde am 30. Oct. 1889 die Enucleation des Stumpfes vorgenommen. Bereits am anderen Tage hatte die Reizerscheinung am rechten Auge bedeutend nachgelassen und im weiteren Verlauf verloren sich dieselben, ohne dass das Auge irgendwie behandelt wurde, vollständig, so dass Patient am achten Tage mit entzündungsfreiem Auge und $\mathrm{S}^{1 / 2}$ entlassen werden konnte. Patient hat seine frühere Arbeit wieder aufgenommen und bis jetzt (Januar 1892) keine Beschwerde von Seiten seines Auges wieder gehabt." 
Diesen Bericht gab mir Herr College Mayweg tit vorher war er schon so freundlich gewesen, mir das enucleirte linke Auge zu ubersenden. Bei der mikroskopischen Untersuchung desselben ist mir mein Assistent, Herr Dr. Weinbaum in dankenswerthester Weise behulflich gewesen.

Der am 15. Januar 1890 aus Müller'scher Flüssigkeit in Alcohol übertragene Bulbus hat einen grössten sagittalen Durchmesser von ca. $16 \mathrm{~mm}$, einen grössten Breitendurchmesser von $22 \mathrm{~mm}$. Der Durchmesser der abgeflachten Cornea beträgt $5 \mathrm{~mm}$. Der Bulbus ist von unregelmässiger Obertäche, partiell abgeplattet und eingeknickt. Am hinteren Pole sind Muskelstreifen und Orbitalfett haften geblieben. Die Durchschneidung geschah durch einen Frontalschnitt, der etwas hinter die Aequatorebene fiel. Die Netżhaut war total abgelöst und bildete einen Strang, der von der Papille aus nach vorn ging und sich, etwa $2 \mathrm{~mm}$ von der geschrampften Linse entfernt, zu einem an dem Ciliarkörper endenden Trichter erweiterte, in welchem sich eine grawweisse, ziemlich feste Masse befand. Der Zwischenraum zwischen Netzhsut und Chorioidea war mit einer, krümliche Massen enthaltenden Flüssigkeit gefüllt. Die $4 \mathrm{~mm}$ im grössten Durchmesser haltende Linse lag der Cornea zum Theil dicht an, zum Theil ist sie, beziehentlich die Iris, durch einen schmalen, $0,5 \mathrm{~mm}$ breiten Schlitz von ihr getrenint. Das Corp. ciliare ist verdickt, die Hornbaut geschrumpft. Der Sebnerv, dicht am Bulbus abgesehnitten, ist fast nur noch im Scleralloch enthalten; die Lederhaut hat sich ringsherum wallartig etwas hervorgebuchtet.

Die Untersuchung richtete sich vorzugsweise auf die Beschaffenheit des Sehnervenrestes und der Ciliarnerven, sowie auf das Vorhandensein yon Bacterien. Es wurden zu diesem Zweck die verschiedenen Färbungsmethoden angewandt, so besonders mit Carmin, Haematoxylin nach Weigert, Löfler'schem Methylenblau, Anilinwasser, Gentiana-Violett.

Was zuerst das Vorhandensein von Bacterien betrifft, so ergab die Untersuchung zahlreicher Präparate ein durchaus negatives Resultat. Auch das in Alcohol aufbewahrte, bei der Nenrectomie abgeschnittene Opticns-Stück wurde in Querschnitte zerlegt. Es fanden sich überall normale Verhältnisse, weder im Opticus selbst noch in dem Zwischenscheidenraum whren abnorme Zellenanhäufungen oder Bacterien nachweisbar. Das kleine Sehnervenstückchen, was uns an beziehentlich in dem Scleralloch des enucleirten phthisischen Bulbus zur Disposition 
stand, war vollkommen atrophisch: der Querschnitt verkleinert, die Bündelanordnung nicht mehr deutlich, das interfibrilläre Bindegewebe verbreitert mit vielen Kernen durchsetzt, die Centralgefässe obturirt, in der Peripherie einige offene Gefässe. Mit Carmin trat ausgeprägte Rothfärbung des ganzen Schnittes ein; die Weigert'sche Färbung zeigte ebenfalls die Atrophie. Querschnitte, die noch etwas rückwärts von dem OpticasReste das anhaftende Gewebe trafen, zeigten Ciliarnerven und Gefässe. Die ersteren waren hier, wie auch in den dem Bulbus näher liegenden Schnitten, atrophisch: nirgends traten in den einzelnen Fasern Markscheide und Achsencylinder scharf hervor, ihre Querschnitte sind durch Carmin gleichmässig roth gefärbt. Ebenso versagte die Weigert'sche Färbung; allerdings zeigte sich gelegentlich in einzelnen Markscheiden eine dunkelbläuliche Färbung, doch war sie weniger intensiv, als wir sie an normalen Nervenfasern, die des Vergleiches wegen aus derselben Gegend entnommen und in derselben Weise gefärbt waren, beobachten konnten. Auch wurden grössere Aeste der Ciliarnerven dem Suprachorioideal-Raume entnommen und theils in Zerzupfungs-, theils in Schnittpräparaten untersucht. Die mit Carmin (bezw. Gentiana-Violett) gefärbten zeigten zahlreiche, langgestreckte Zellenkerue zwischen den atrophischen Fasern; die Weigert'sche Färbung trat nur hier und da andeutungsweise hervor. Auffälliger Weise fand sich jedoch auf Querschnitten des Corpus ciliare an einzelnen wenigen Nervenfasern eine intensive Färbung, so dass hier noch eine normale Beschaffenheit derselben anzunehmen ist. Es sitzen die betreffenden Fasern besonders dicht unter der Sclera in dem von zahlreichen Blutzellen infiltrirten Suprachorioideal-Gewebe, aber einzeIne, gut gefärbte Nerven, selbst zu kleinen Bündeln vereint, liegen auch zwischen den angrenzenden Muskelfibrillen des Ciliarkörpers. Erhaltene Nervenfasern finden sich gleichfalls in der Cornea, sie liegen vorzugsweise in der Peripherie, von wo sie mit den Gefässen in die bindegewebig entartete Hornhaut bündelweise hineinziehen (cf. die Abbildungen). Bemerkenswerth sind die vielfachen Blutungen: so finden sich auch Blutmassen in der vorderen Kammer, in der Iris, selbst in der Linse, welch' letztere neben Myelintropfen und zum Theil ungewöhnlich grossen Rundzellen verhältnissmässig nur wenige Linsenfasern zeigt. Auch in den Massen, welche hinter der Linse in dem Netzhauttrichter liegen, sind zahlreiche Blutkörperchen angehäuft. Die Chorioidea zeigt viele anastomosirende 
Blutgefässe, die fast einem schwammähnlichen Höhlensystem gleichen. -

Es liegt uns hier die bisher noch nicht gemachte Beobachtung vor, dass nach einer Neurectomie mit Resection eines Stückes Opticus von $1 \frac{1}{2} \mathrm{~cm}$ Länge $11 / 2$ Jahre später eine sympathische Ophthalmie ausbricht. An eine zur Zeit der Ausführung der Resection eingeleitete Uebertragung ist nicht zu denken; in dem von Clausen in seiner Dissertation mitgetheilten äbnlichen Fall (Kiel 1886) ist diese Vermuthung naheliegend. Die sympathische Natur der Affection aber erscheint nach der Schilderung des Herrn Collegen Mayweg als gesichert, zumal alle sonstigen ätiologischen Momente fehlten; auch die Beobachtung, dass jeder, auch der leiseste Druck auf den phthisischen Augapfel eine stärkere Injection des anderen Auges hervorrief, duirfte von pathogenetischer Bedeutung sein. Eine ähnliche Beobachtung haben wir in dem folgenden Falle gemacht.

2) Sympathische Ophthalmie ohne vorausgegangene Druck-Empfindlichkeit. Als erstes Symptom Iritis serosa. Steigerung der Entzündung durch erneutes Trauma des primär verletzten Auges. Heilung.

August R., 12 Jahre alt, wurde am 26. April 1891 von einem wallnussgrossen Stein in das linke Auge getroffen. Bei der noch am selbigen Tage vorgenommenen Untersuchung fand sich am oberen inneren Theile des Augapfels eine ca. $5 \mathrm{~mm}$ lange perforirende Wunde, die halb in der Sclera und halb in der Coruea lag. Etwas aussen vom Sclerallimbus war ein hirsekorngrosser Vorfall von Iris. Vordere Kammer flach, kleines Hyphaema. Pupille oval, nach der Wunde verzogen, auf der Linse etwas Blut. Mit dem Angenspiegel kein deutlicher rother Reflex. Keine Druckempfindlichkeit, kein spontaner Schmerz. Handbewegung in $1 / 3 \mathrm{~m}$; kleinste Lampe, gute Projection. Ausspülen des Auges mit Aqua chlorata und Druckverband. Die Heilung schritt gut voran, am 10. Mai zäblte Patient Finger in nächster Nähe. 12. Mai Abtragen des Irisprolapses mittelst Lappenschnittes mit dem Schmalmesser und folgender Scheeren-Umschneidung. 19. Mai. Gutes Aussehen des Auges, das nur mässig injicirt ist. Gute Spannung, keine 
Druckempfindlichkeit. Dieser Zustand besteht noch, als am 22. Mai am rechten Auge eine leichte pericorneale Injection bemerkt ward. Die ophthalmoskopische Untersuchung zeigt nichts Abnormes, nach Atropin-Einträufelung erweitert sich die Pupille maximal. $\mathrm{S}=1$. Am folgenden Tage klagt Patient über zeitweilige Schmerzen im rechten Auge; das Corp. ciliare ist an einzelnen Stellen auf Druck empfindlich. Geringe pericorneale Injection; Thränen. Auge gut gespannt. Aber an einer kleinen Stelle der Membr. Descemetii findet sich eine zarte Auflagerung, so dass die Hornhant daselbst wie bestäubt aussieht. Die Iris ist ein wenig verfärbt, Pupille trotz Atropin kaum mittelweit. Bei der ophthalmoskopischen Untersuchung ist der Glaskörper klar, die Papilla optica erscheint etwas geröthet, da aber die Fovea noch weiss ist, kann man den Befund nicht für pathologisch erklären. Die Venen sind etwas geschlängelt. Das linke Auge ist nicht besonders gereizt, gut gespannt, sowohl auf Druck als spontan absolut unempfindlich. Man erhält vom Angenhintergrunde rothes Licht. $\mathrm{S}^{4} / 36$. Bei diesem Sehvermögen und unter weiterer Erwägung, dass bei einmal ausgebrochener sympathischer Ophthalmie die Enucleation durchaus nicht immer den Process zum Schwinden bringt, wird von der Entfernung des zuerst verletzten Auges Abstand genommen und eine Schmier-Cur eingeleitet. Dabei Aufenthalt in Dunkelzimmer, was erfahrungsgemäss bei sympathischer Affection von grosser therapeutischer Bedeutung ist, Atropin, Blutegel. Das Auge, bei dem sich die Iritis weiter entwickelt hatte, wurde allmälig wieder blasser; am 29. Mai ist notirt, dass beide Augen gut gespannt und weder spontan, noch auf Druck empfindlich sind. Als am 15. Juni das rechte Auge wieder zum ersten Male ophthalmoskopirt wurde, fanden sich Glaskörpertrübungen, die Papille war hyperämisch und geschwollen. Am 18. Juni wurde die Schmier-Cur, die sieben Tage ausgesetzt war, wieder aufgenommen. Das rechte Auge ist blass, röthet sich jedoch leicht bei Lichteinfall. Am 20. Juni Abends wurde Patient, der aufgestanden war, von einem anderen Knaben heftig gegen das linke Auge gestossen, so dass Sugillationen im Lide auftraten. Am folgenden Tage ist auch das rechte Auge erheblich stärker injicirt, Pupille enger, lichtschener. Erst am 24. sind beide Augen wieder reizloser. - Nach und nach trat eine dauernde Besserung ein, auch ophthalmoskopisch lichteten sich die Glaskörpertrübungen und die Papilla optica wurde flacher und weniger verschwommen. Aber man kounte jetzt bei genauerer 
Untersuchung in der Peripherie kleine meist rundliche weisse chorioiditische Herde erkennen, die nur vereinzelt schwärzliche Pigmentirung zeigten. Auch die Descemetitis, die sich im Laufe der Erkrankung ausgebildet hatte, ging mehr zurück, so dass das rechte Auge bei guter Spannnng Anfang December S fast 1 hatte and äusserlich und innerlich fast normal aussah. Das linke Auge, dessen Papilla optica man deutlich erkennen kann - sie war noch etwas getrübt, aber ziemlich scharf abgegrenzt -, besass $S=1 / 4 ;$ Spannung und Aussehen waren gut.

Beide oben mitgetheilten Fälle lassen sich durch die Migrations-Theorie nicht erklären: im Gegentheil, sie widersprechen ihr direct. Bei dem ersten Patienten ist die sympathische Ophthalmie erst $11 / 2$ Jahr nach der Neurectomia optico-ciliaris entstanden. Wenn man selbst zur Erklärung der später auftretenden sympathischen Ophthalmie an eine Einkapselung und dadurch bedingte Unthätigkeit der Mikrobien denken wollte, so fehlt doch jede Begründung dafür, dass überhaupt Mikrobien aus dem erstverletzten Auge ursprünglich in das andere hinübergewandert sind. Sowohl der enucleirte Bulbus wie das resecirte Nervenstück waren bacterienfrei. Uebrigens sind Beobachtungen, bei welchen sich das nach eingetretener sympathischer Ophthalmie enucleirte Ange bacterienfrei erwies, jetzt schon in ziemlicher Anzahl vorhanden; die bezüglichen Untersuchungen sind zum Theil mit allen möglichen Kautelen der bacteriellen Technik durchgefuhrt. So fand Nordenson in einem von Hirschberg (bei einer 14 Tage bestehenden Ophthalmie) enucleirten Auge, das in Koch's Laboratorium untersucht wurde, keine Mikroorganismen; denselben negativen Befund gaben Berry (14 Augen), S. C. Ayres und Adolf Alt (1 Auge), Randolph (3 Augen), und neuerdings Kuhntr) an (hier wurde die Untersuchung von dem Jenaenser Bacteriologen Gärtner geführt). In der Schweigger'schen Klinik wurden 30 Opticus-Stücke, welche bei der Neurectomia op-

1) Heidelberger Congress 1891. 
Beitrag z. Aetiologie u. Prophylaxe d. sympathischen Ophthalmie. 207

tico-ciliaris resecirt waren, auf Bacterien untersucht: nicht in einem einzigen Präparat hat sich ein Micrococcus nachweisen lassen ${ }^{1}$ ). Bemerken will ich jedoch, dass nur einige der erwähnten Untersuchungen an Augen, die wegen wirklich ausgebrochener sympathischer Ophthalmie enucleirt wurden, ausgeführt sind: nur diese können natürlich für unsere Frage entscheidend sein. Aber sie beweisen eben auch, vollkommen in Uebereinstimmung mit dem von mir oben mitgetheilten Fall, dass sympathische Ophthalmien auftreten, ohne dass Mikroorganismen in dem primär verletzten Auge vorhanden sind. Dem gegenüber können positive Befunde von Bacterien in enucleirten Augen nicht ausschlaggebend sein. Bekanntlich hat Deutschmann, dem wir so vielfältige Untersuchungen über diese Frage verdanken, in 15 darauf hin untersuchten Fällen 14 mal Coccen, Diplo-Cocen beziehentlich Stäbchen gefunden, nur einmal vermisste er sie: betreffs dieses Falles sagt er „doch beweist das nur, dass ich keine Mikroorganismen in den von mir angefertigten Präparaten gefunden habe, aber nicht, dass keine in dem Auge irgendwo vorhanden sind ${ }^{2}$ )." Dieser Einwand lässt sich bei allen bacteriellen Untersuchungen machen; er wird aber um so unwahrscheinlicher, je exacter die Nachforschungen, besonders wenn sie mit Cultur-Versuchen verknüpft sind, ausgeführt wurden. Und selbst wenn Bacterien in allen untersuchten Augen gefunden worden wären, so ist damit noch nichts für die migratorische Theorie erwiesen, da man eben auch in Augäpfeln, welche keine sympathische Ophthalmie veranlassen, gelegentlich Mikrobien findet. Dies trifft als Regel besonders für die Panophthalmitis zu, wo theils Coccen theils Bacillen oder auch beide Formen nachgewiesen sind.

1) Ohlemann, Die perforirten Augenverletzungen etc. KnappSchweigger's Arch. f. Augenheilk. XXII. S. 94.

2) Ueber die Ophthalmia migratoria. S. 63 . 
Ich selbst habe meist nur Coccen, gelegentlich aber auch Coccen mit sehr vereinzelten Stäbchen gesehen. Nach diesem Befunde müssten grade bei der Panophthalmitis besonders häufig sympathische Ophthalmien entstehen, wenn sie durch wandernde Mikrobien veranlasst würden. Die klinische Erfahrung lehrt aber das Gegentheil; selbst die nach Panophthalmitis phthisisch gewordenen Augäpfel bieten weniger Gefahr als die durch Irido-Cyclitis geschrumpften. Sollte wirklich bei einer floriden Panophthalmitis, die natuirlich klinisch von der einfachen Chorioiditis suppurativa zu trennen ist, einmal eine sympathische Ophthalmie ausgebrochen sein, so ist das gewiss ein ganz besonderer Ausnahmefall. Wenn im Gegensatz hierzu Alt ${ }^{1}$ ) in seinen Studien über sympathische Ophthalmie angiebt, in 110 wegen ausgesprochener oder befurrchteter sympathischer Ophthalmie enucleirten Bulbi 21 mal „purulente Panophthalmitis" gefunden zu haben, so ist zu beachten, dass es sich bei ihm um eine anatomische Diagnose handelt, die er auf Rundzelleninfiltration im Uveal-Tractus basirt: die gelegentlich mitgetheilten Krankengeschichten (z. B. Fall 20, 31) lehren aber, dass eine klinische Panophthalmitis nicht vorlag.

Deutschmann glaubt mit Leber die Erklärung für das „weniger häufige Auftreten“ der Entzündung des zweiten Auges bei Panophthalmitis des ersten darin zu finden, „dass die Entzïndungserreger theils bei der eitrigen Perforation der Bulbushüllen mit dem Eiter nach aussen entleert, theils durch die massenhafte Eiterbildung unwirksam gemacht, beseitigt und zerstört werden." Hiergegen ist jedoch einzuwenden, dass wenigstens im Beginn der Entzündung eine Ueberwanderung eintreten könnte; aber auch selbst nach längerem Bestehen finden sich lebensfähige Bacterien im Auge. So habe ich durch Impfung aus dem Augen-Innern einer bereits 4 Wochen bestehenden Panophthalmitis noch Staphylo-

1) Arch. f. Augen- und Ohrenheilkunde. VI. 
Beitrag z. Aetiologie u. Prophylaxe d. sympathischen 0phthalmie. 209

coccus pyogenes aureus gezüchtet, welcher in die KaninchenHornhaut geimpft sehr intensive eitrige Entzündungen bewirkte. Allerdings lässt sich hiergegen sagen, wie es Leber auf dem Heidelberger Congress gethan, dass durch derartige Experimente nur ein Wahrscheinlichkeits-Beweis dafür geführt werde, dass der Staphylococcus nicht der Uebertrager der sympathischen Ophthalmie sei. Aber die Theorie, wie sie besonders Deutschmann entwickelt hat, ist grade auf dem Staphylococcus aufgebaut! Deutschmann ist es bekanntlich gelungen, durch Einspritzung dieses Pilzes in den Glaskörper des Kaninchens entzündliche Veränderungen im anderen Auge hervorzurufen und auch, wie die Abbildung in seiner Schrift „Ueber Ophthalmia migratoria etc." zeigt, Staphylococcen sowohl in der Sehnervenscheide des primär wie des secundär erkrankten Auges nachzuweisen: hierauf beruht eben die ganze Anschauung über das Zustandekommen der Ophthalmia migratoria, soweit sie auf experimentelle Begründung Anspruch erheben kann.

Zum Schaden der Theorie aber haben selbst diese Untersuchungen, soweit der Staphylococcus pyogenes in Betracht kommt, keine Bestätigung gefunden (Gifford, Mazza, Randolf, Ovio, Basevi, Limbourg und Levy): die Deutung der Deutschmann'schen Ergebnisse dürfte darin liegen, dass die von ihm geimpften Kaninchen an Alggemein-Infection, wie auch aus seinen Mittheilungen zum Theil erweislich, zu Grunde gegangen sind, wobei dann eben die Staphylococcen auch in den Sehnervenscheiden sich finden. Gegen die negativen Befunde der anderen Autoren lässt sich nicht wohl einwenden, ,dass die Versuchs-Bedingungen schwer zu erfüllen seien ${ }^{1}$ ), "wenn Deutschmann selbst berichtet ${ }^{2}$ ): „Die Zahl meiner Versuche beläuft sich mit den neuerdings von mir angestellten auf mindestens vierunddreissig, worauf zwölf

1) L, eber, 7. internat. Ophthalmologen-Congress. S. 360.

2) 1. c. S. 39 .

r. Graefe's Archiv für Ophthaimologie. XXXVIIr, 1. 
positive Erfolge linsichtlich ophthalmoskopisch und mikroskopisch nachweisbarer Affection des zweiten Auges kommen': das sind über $30 \%$ positive Erfolge. Bei einer solchen Anzahl kann der Nicht-Erfolg der anderen Autoren kaum auf reines "Ungluick" geschoben werden. Wohl hat Gifford bei Injection von Milzbrand-Bacillen in den Glaskörper ein Vorkommen derselben in dem Perichorioidealraum des andern Auges beobachtet, aber ausdrücklich betont er, dass die Ueberwanderung in den Schädelraum nicht, wie Deutschmann will, durch den subvaginalen Raum des erstafficirten Auges erfolge. Bei dem eigenthümlichen Wachsthum der Milzbrand-Bacillen, zumal es sich selbstverständlich bei sympathischer Ophthalmie nie um diese handeln kann, dürfte wohl kein besonderes Gewicht auf diese Ergebnisse betreffs der Art und des Weges der Uebertragung zu legen sein. Basevi hingegen, dem die StaphylococcenInjectionen auch negative Resultate ergaben, hat durch Einimpfung von Bacillen, die er aus Augen, die wegen sympathischer Ophthalmie enucleirt waren, züchtete, bei Kaninchen eine sympathische Irido-Cyclitis einige Male hervorgerufen. Es dürfte hier jedoch abzuwarten sein, ob weitere Bestätigungen einlaufen, zumal die Möglichkeit vorliegt, dass die betreffenden Kaninchen an einer primären Irido-Cyclitis litten: eine Möglichkeit, welche die interessanten Mittheilungen Ed. Meyer's (Heidelberger Congress 1891) nahelegen. Uebrigens vermitteln nach Basevi ausser anderen Wegen auch die Blutgefässe die Uebertragung. Limbourg und Levy ${ }^{1}$ ) züchteten aus drei wegen sympathischer Ophthalmie enucleirten Augen einen Coccus, der dem Staphylococcus cereus albus von Rosen bach sehr ähnlich sab; aber auch mit diesem erreichten sie keinen positiven Erfolg bei der Injection in den Glaskörper. Bekanntlich hatte schon Sattler auf dem internationalen ophthalmologischen Con-

1) Archiv für experimentelle Pathologie und Pharmacologie. XXVIII, 1890. 
Beitrag z. Aetiologie u. Prophylaxe d. sympathischen Ophthalmie. 211

gress 1890 den Verdacht der sympathischen Thäterschaft auf eine besondere Species von Mikrococcen gelenkt, die er aus zwei sympathischen Augen geziichtet hatte und die sich von dem Staphylococcus pyogenes albus, mit dem sie eine gewisse Aehnlichkeit hatte, unterschied; ihm hat es „, von jeher widerstanden, daran zu glauben, dass einer der vorhin erwähnten Eiterbacterien Erreger der sympathischen Ophthalmie sein sollte ${ }^{1}$ )." Besonders spricht ihm dagegen, dass die Staphylococcen Eiterung veranlassen, während im sympathischen Auge serös-fibrinöse, zur Bildung organisirter Schwarten tendirende, schleichende Entzündungen vorhanden sind. Auch kann er nicht annehmen, dass die Wanderung centripetal durch die Sehnervenscheide nach dem Gehirn hin erfolge, da dies dem Lymphstrom entgegen liefe.

Bis jetzt liegt demnach die Sache so, dass weder der Weg experimentell nachgewiesen ist, auf dem eine Wanderung von Bacterien von dem primär ergriffenen Auge zu dem sympathisch erkrankten erfolgt, noch, dass wir die vermutheten sympathischen Wander-Bacterien kennen. Irgend welcher zwingende Beweis für die Richtigkeit der Migrations-Theorie besteht demnach nicht. Der Fall, den ich oben mitgetheilt, zeigt im Gegentheil, dass ohne Vorhandensein des Opticus und ohne Bacterien eine sympathische Ophthalmie ausbrechen kann. Selbstrerständlich will ich die Möglichkeit einer gelegentlichen Uebertragung im Sinne der Migrations-Theorie nicht ablehnen; aber in der überwiegenden Mehrzahl der Fälle dürfte die Uebertragung, wie sich aus den klinischen Beobachtungen ergiebt, in dieser Weise eben nicht stattfinden. So wird, um neben dem oben Erwähnten noch Einiges anzuführen, in der Regel zuerst in den vorderen Partien der Uvea der sympathische Krankheitsprocess beobachtet, nicht in dem Opticus oder den hinteren Partien der Uvea. In dem zweiten von mir

1) 7. internat. Ophthalmologen-Congress. S. 383 . 
mitgetheilten Fall waren bereits Beschläge an der Membrana Descemetii, während die Papilla optica noch keine pathologische Hyperaemie zeigte; in einem Falle von H. Pagenstecher wurde bei ausgeprägter sympathischer Irido-Cyclitis „mit absoluter Gewissheit constatirt, dass Anzeichen von Papillitis oder Neuroretinitis vollständig fehlten $\left.{ }^{1}\right)^{*}$. Dass übrigens Hyperaemien der Papille auch bei gewöhnlicher Iritis und Chorioiditis vorkommen, ist bekannt; es sind demnach für die primäre Affection des Sehnerven nur die Fälle beweiskräftig, bei denen eine ausgeprägte pathologische Veränderung an der Papille wahrgenommen wird, während das Auge im übrigen vollkommen entzündungsfrei ist. Ferner sei an die klinisch allgemein anerkannte besondere Gefährlichkeit der Verletzungen des Corpus ciliare und der in diesem verlaufenden schleichenden Entzündungen sowie an die Bedeutung der Druckempfindlichkeit erinnert, welche in der weit überwiegenden Mehrzahl der Fälle uns auf die Gefahr einer sympathischen Erkrankung aufmerksam macht: alles Erscheinungen, die in der Migrations-Theorie keine ausreichende Erklärung finden.

Ein sehr gewichtiges Argument gegen diese Theorie wird durch die Arbeit Ohlemanns ${ }^{2}$ ) gebracht, welcher das Material von Schweigger verwerthet. Unter 556 schweren Verletzungen traten nur zwei Mal sympathische Entziundungen auf. Trotzdem in 46 verletzten Augeu Eiterungen bestanden, die lange genug währten, um eine Migration zu Stande kommen zu lassen, ferner in 45 Fällen das längere Verweilen von Fremdkörpern, denen doch gelegentlich Mikroorganismen anhaften mussten, im verletzten Bulbus nachweisbar war, so blieb doch in all diesen Fällen die sympathische Ophthalmie aus.

Nach alledem erscheint mir auch aus klinischen Gründen

i) Scheffels, Ueber Sehnerven-Resection. Klinische Monatsbl. 1890 . S. 235 .

s) 1. c. 
Beitrag z. Aetiologie u. Prophylaxe d. sympathischen Ophthalmie. 213

die Migrations-Theorie für die überwiegende Mehrzahl der Fälle nicht annehmbar. Meines Erachtens giebt die alte Ciliar-Nerven-Theorie mit einer gewissen Modification immerhin noch die beste Erklärung für das Zustandekommen der sympathischen Ophthalmien. Betreffs der einfachen sympathischen Neurosen wird selbst von den Verfechtern der bacteriellen Migration die reflectorische, auf das zweite Auge wirkende Nerven-Reizung als Ursache angenommen: nur die Entstehung der eigentlichen sympathischen Entzündung auf diesem Wege wird, da sie ohne Analogie dasteht, abgelehnt. Wir müssen in der That zugeben, dass hier eine gewisse Lücke vorhanden ist, obgleich mancherlei Gewebsveränderungen, wie wir sie bei sympathischen Affectionen finden, wohl auch in Aualogie zu setzen wären mit den Erscheinungen, die durch Einwirkung vasomotorischer oder trophischer Nerven an anderen Stellen hervorgerufen werden. So bewirken nach Heidenhain's Untersuchungen die trophischen Nerven der Schleimdrïsen nachweisbare morphologische Veränderungen der Zellen; Max Joseph hat durch Zerstörung trophischer Nerven eine besondere Form von Haarausfall bei Katzen zu Stande gebracht. Dass Reizung eines Auges Hyperaemie des anderen hervorruft, können wir klinisch oft genug beobachten; in dem von mir oben mitgetheilten zweiten Fall war eine erneute Röthung und Zunahme der Entzündung als unmittelbare Folge eines Stosses auf das primär erkrankte Auge zu constatiren. Auch experimentell ist durch Mooren und Rumpf erwiesen, dass die Reizung der Irisnerven eines Auges zuerst einen Gefässkrampf und dann eine Hyperaemie am anderen Auge hervorruft. Aber zwischen der Hyperaemie und der trophischen Störung einerseits und der eigentlichen Entzündung andererseits fehlt noch das Mittelglied: es bedarf hierzu eines neu hinzutretenden entziindungerregenden Momentes. So meine ich denn, dass die Reizung der Ciliarnerven in dem verletzten Auge durch eine reflectorisch eingeleitete Störung in der Blutcirculation und Ernährung 
einzig und allein die Disposition zur sympathischen Entzündung des anderen Auges giebt. Je länger die Veränderungen bestehen und je ausgedehnter sie sind, um so mehr ist der Boden für die Einwirkung von entzündungserregenden Schädlichkeiten (seien sie bacterieller oder chemischer Art) vorbereitet. Dieselben Schädlichkeiten, welche in einem gesunden Organ leicht und ohne Nachtheil überwunden werden, können hier zu den gefährlichsten und zerstörendsten Processen führen; treten keine solche Schädlichkeiten hinzu, so kommt es auch nicht zu einer sympathischen Ophthalmie. Bei dieser Auffassung wird es verständlich, dass bei sonst gleichen Formen von Verletzungen einmal die sympathische Affection auftritt, das andere Mal ausbleibt. Auch die verhältnissmässige Seltenheit ihres Vorkommens, sowie die grossen Zeit-Differenzen, welche zwischen dem Ausbruch der sympathischen Entzündung und der primären Verletzung in den einzelnen Fällen liegen, finden darin ihre Erklärung, dass eben zu der "sympathischen Disposition" noch die besondern, entztindungmachenden Schädlichkeiten hinzukommen müssen. Da durch die reflectorische Wirkung der gereizten Ciliarnerven vorzugsweise Störungen in dem Gebiete der Uvea angeregt werden, so wird es in der Regel auch zu Erkrankungen dieser Membranen kommen; aber je nach der Art der Schädlichkeiten können sehr verschiedenartige Formen auftreten, so die verhältnissmässig günstig verlaufende Iritis serosa, oder die schwere, wie man sagt, typische sympathische Irido-Cyclitis oder gelegentlich selbst eine einfache Chorio-Retinitis. Sollte man einmal wirklich die bisher incognito wandernde sympathische Bacterie entdecken, so würde es immerhin etwas auffallen, dass ein und derselbe specifische Pilz im Auge diese so verschiedenartigen Processe hervorrufen könnte. Darüber aber, dass die sympathische Ophthalmie nicht einzig and allein als schwere Irido-Cyclitis auftritt, kann nach meinen Beobachtungen wenigstens kein Zweifel bestehen; 
Beitrag z. Aetiologie u. Prophylaxe d. sympathischen Ophthalmie. 215

speciell habe ich verschiedene Male eine Iritis serosa mit Glaskörpertrübungen als sympathische Affection entstehen sehen. Allerdings könnte ein Gegner dieser Ansicht den strikten Beweis verlangen, dass diese Iritis serosa wirklich eine sympathische gewesen sei und alle Wahrscheinlichkeitsgründe damit zurückweisen, dass Iritis serosa auch sonst vorkomme, und demnach das betreffende Individuum neben seiner einseitigen Augenverletzung ganz unabhängig von dieser von einer Iritis serosa des anderen Auges befallen worden sei. Hiergegen lässt sich nur einwenden, dass der gleiche Zweifel auch betreffs der sympathischen Irido-Cyclitis erhoben werden könnte, da gelegentlich Formen von Irido-Cyclitis ohne vorhergegangene Verletzungen beobachtet werden, die den sogenannten typischen sympathischen in ihrem Auftreten und Verlauf vollkommen gleichen. Ich habe derartige Fälle, besonders bei jugendlichen Individuen und doppelseitig auftretend, gesehen, wo es zu totalen Verwachsungen der degenerirten Iris mit der Linsen-Kapsel, Verengung der vorderen Kammer und selbst vereinzelt zur Phthisis bulbi kam. Also eine für die sympathische Ophthalmie typische Form der Erkrankung, die ihr einzig und allein zukäme, giebt es nicht; wir werden stets nur den ätiologischen Zusammenhang mit der vorangegangenen Verletzung auf Grund unserer allgemeinen klinischen Erfahrungen und gewisser Wahrscheinlichkeits-Gründe annehmen können. Unter letzteren wird besonders von Bedeutung sein, dass ein bisher mit gesunden Augen versehenes Individuum nach einer schweren Verletzung, die ein Auge trifft und eine Irido-Cyclitis veranlasst, ohne direct erweisliche ätiologische Momente noch von einer schweren Erkrankung des Uvealtractus des anderen Auges befallen wird. Würde hier die Enucleation des erstverletzten Auges die Erkrankung des anderen sofort heben, so dürfte wohl damit die Gewissheit der sympathischen Natur derselben gegeben sein; bekanntlich aber trifft das auch bei allgemein als sympathisch angesehenen Erkrankungs- 
Fällen meist nicht zu. Mit absolut sicheren Beweisgründen für die sympathische Natur der betreffenden Krankheiten, soweit sie in dem einzelnen Falle gegeben werden sollen, ist es demnach überall schlecht bestellt: die aus einer grossen Reihe von ähnlichen Beobachtungen gezogene Erfahrung muss hier den Ausschlag geben. -

Wenn wir nach obigen Auseinandersetzungen wieder darauf zurückgekommen sind, in einer Reizung der Ciliarnerven des verletzten Auges die erste Ursache beziehentlich Disposition für Entstehung sympathischer Ophthalmien zu suchen, so werden wir bei unseren prophylactischen Operationen auf eine einfache Durchschneidung des Sehnerven (Neurotomia optica), wie sie neuerdings von $\nabla$. Wecker empfohlen ist, von vornherein als unzureichend verzichten müssen. Dasselbe gilt auch für die einfache Neurotomia optico-ciliaris, da ohne ausgiebige Stellungsveränderung des Bulbus und der ihm anliegenden Gewebe ein Zusammenwachsen der durchschnittenen Nerven nicht ausgeschlossen ist. Aber: wie mein oben mitgetheilter Fall lehrt, schützt selbst eine grössere Resection des Sehnerren (Neurectomia optico-ciliaris) mit rollkommener Umdrehung des Bulbus und ausgiebigerem Abrasieren des hinteren Augenrestes nicht gegen den Ausbruch einer sympathischen Ophthalmie: die Untersuchung des schliesslich enucleirten Stumpfes hat ergeben, dass dennoch einzelne wohlerhaltene Nerven im Corpus ciliare vorhanden waren. Auch in der Cornea verliefen Nervenbündel, die von den Conjunctivalnerven herstammten: man sieht sie von der Peripherie mit den Gefässen in die Cornea dringen. Uieses Hineinwachsen der Nerven in die Cornea dürfte bei den neurectomirten Augen sehr häufig sein. Wenn auch gleich nach der Operation die Cornea in ihren centralen Partien empfindungslos ist - an einzelnen Partien der Peripherie besteht meist noch Empfindlichkeit -, so pflegt doch nach längerer Zeit die Sensibilität wieder in grösserer Ausdehnung hergestellt zu sein. 
Beitrag z. Aetiologie u. Prophylaze d. sympathischen Ophthalmie. 217

Wichtiger für uns ist die Frage nach dem Herkommen der einzelnen Nerven, welche sich in Corpus ciliare noch erhalten finden, da doch alle anderen Nerven, die von den hinteren Ciliarnerven stammen, atrophisch geworden waren. Es giebt zwei Möglichkeiten: einmal könnte ausnahmsweise ein Ciliarnerv soweit nach vorn seinen Durchtritt durch die Sclera nehmen, dass er bei der Operation, welche doch nur den hinteren Abschnitt des Augapfels trifft, verschont geblieben wäre, oder wir haben es mit einem normalen anatomischen Befunde zu thun, wodurch ähnlich wie bei der Hornhaut ein Hineinwachsen von früher vielleicht nicht vorhandenen Nervenfasern erklärt wird. Letzteres ist nach den Untersuchungen von Bou cheron ${ }^{1}$ ) am Meerschweinchenauge in der That annehmbar. Danach senden die oberflächlichen, von den Orbital-Nerven abstammenden und im episcleralen Gewebe verlaufenden Nerven (Nerfs ciliaires superficiels) in der Umgebung der Cornea mit den vorderen Ciliar-Gefässen perforirende Aeste in die Sclera, welche zusammen mit den tiefen, von den hinteren Ciliarnerven abstammenden Nerven einen anastomosirenden Plexus (Grand plexus scléral interciliaire) bilden, von dem aus vorzugsweise die tieferen Hornhautnerven abgehen, aber auch in den Ciliarkörper hinein Aeste gesandt werden. Es ist naheliegend, dass von hier aus nach Durchschneidung der hinteren Ciliar-Aeste eine Neu-Versorgung einer Partie des Corpus ciliare mit Nervenfasern eintreten kann. Damit erklärt sich auch das einige Male beobachtete Wiederauftreten der Druckempfindlichkeit nach der Neurectomie. Mit der Neubildung der Nerven im Ciliarkörper rückt aber die Gefahr einer sympathischen Ophthalmie näher, wie der von mir mitgetheilte Fall lehrt.

Es fragt sich, ob wir unter diesen Verhältnissen ein

1) Nerfs de l'hémisphère antérieur de l'oeil. Extrait des comptes rendues de la Société de Biologie. Paris 1890. 
für alle Male aut die Neurectomia optico-ciliaris verzichten sollen. Scheffels, der über eine grössere Zahl von Neurectomien aus H. Pagenstecher's Klinik berichtet, meint, dass ein einziger Fall einer sympathischen Ophthalmie nach einer rite ausgeführten Resection diese Operation für die Zukunft verwerflich erscheinen lassen würde. Ich möchte mich dieser Ansicht nicht unbedingt anschliessen, wenn ich die grosse Reihe von Neurectomien übersehe, bei denen dauernd Schutz gegen eine Uebertragung erreicht wurde. Die Vorzüge dieser prophylactischen Operationsmethode, durch welche dem Patienten der Augapfel erhalten wird, sind in manchen Fällen so in's Gewicht fallend, dass ich nicht auf Grund einer einzigen üblen Erfahrung darauf verzichten will. Natürlich kann es sich nur um die eigentliche Neurectomia optico-ciliaris mit Resection eines ausgiebigen Sehnervenstïckes handeln, nicht um die Neurotomia, bei der ein Wiederzusammenwachsen der Nerven möglich ist, wie anatomische Untersuchungen lehren. Auch sind bereits von Leber ${ }^{1}$ ) und H. Pagenstecher ${ }^{2}$ ) Fälle mitgetheilt, in denen nach der Neurotomie eine sympathische Erkrankung aufgetreten ist. Besonders überzeugend ist die Pagenstecher'sche Beobachtung, wo die entzündlichen Erscheinungen sich erst 95 Tage nach der Neurotomie zeigten, also eine zur Zeit der letzteren bereits vorhandene Uebertragung auszuschliessen ist.

Jedoch dürfte es sich unter Berücksichtigung der obigen Befunde empfehlen, in Zukunft die Neurectomia optico-ciliaris noch in der Weise zu vervollständigen, dass in einiger Entfernung von der Cornea vor den Sehnen-Ansätzen subconjunctival eine ausgiebige Scarification rorgenommen wird, um die in die Tiefe dringenden Nerven zu durchtrennen. Technisch hat dies keine besonderen Schwierigkeiten, da

1) Arch. f. Ophthalmologie. XXVII.

2) Klin. Monatsbl. f. Augenheilk. 1890. S. 232. 
Beitrag z. Aetiologie u. Prophylaxe d. sympathischen Ophthalmie. 219

man bei der Neurectomie schon für gewöhnlich die Conjunctiva bis nahe an die Ansätze der Rect. superiores und inferiores löst, um die Umdrehung des Bulbus leicht auszuführen. Betreffs der von mir geübten Methode will ich noch erwähnen, dass ich stets den Internus tenotomire und, worauf ich ganz besonderes Gewicht lege, nach der Durchschneidung des Opticus vor Herumwälzung des Bulbus erst durch Schluss der Lider und Compression die eintretende Blutung stille. Hierdurch habe ich stets einen stärkeren Exophthalmus vermieden, der, wie bekannt, sogar manche Operateure zur Punction des Bulbus oder nachträglichen Enucleation nöthigte. Nur in einem Falle habe ich durch Verschieben des Verbandes am Tage nach der Operation ein Hervortreten des Augapfels zwischen den Lidern beobachtet; doch ging derselbe unter Druckverband wieder zuriick. Das Umwenden des Augapfels bewirke ich durch Einlegen eines scharfen Doppelhaken.

Die Neurectomie wird man mit obiger Modification auch ferner prophylactisch ausführen dürfen, in den Fällen, welche erfahrungsgemäss keine hervorragende Gefahr einer sympathischen Erkrankung bieten: also bei druckempindlichen, an Irido-Cyclitis erblindeten oder fast erblindeten Augen, die nicht durch Trauma zu Grunde gegangen sind, oder auch bei solchen, die zwar traumatisch zerstört sind, aber keinen Fremdkörper enthalten. Gelegentlich wird man aber auch selbst Augen mit Fremdkörpern in dieser Weise operiren müssen, wenn von dem Verletzten die Erlaubniss zur Enucleation oder Exenteration versagt wird. Bei wirklich ausgebrochener sympathischer Ophthalmie sollten erblindete oder fast erblindete verletzte Augen stets enucleirt werden: gelingt es auch nicht immer die Secundär-Affection ganz rückgängig zu machen, so übt man doch meist einen vortheilhaften Einfluss auf den Verlauf derselben. Auch bei sehr ausgedehnten Scleralwunden bleibt uns nur diese Radical-Operation übrig; ebenso bei kleinen Stümpfen mit 
220 H. Schmiat-Rimpler, Beitrag zur Aetiologie und Proplylaxe etc.

Verknöcherungen. Hingegen ziehe ich die Exenteration bei beginnender suppurativer Chorioiditis nach Verletzungen der Enucleation entschieden vor, um keine Gelegenheit zux Infection des Orbitalgewebes zu geben. Ebenso übo ich sie anstatt der Neurectomia optico-ciliaris, wenn das in Erage stehende Auge im Aeussern sehr von der Norm abweicht und der Patient kein Gewicht auf die Erhaltung legt.

Erklärung der Abbildungen auf Taf. X.

Fig. 1. Querschnitt durch die Cornea. Einzelne dunkelgefärbte Nervenfasern liegen neben neugebildeten Gefässen im Hornhautgewebe. Weigert'sche Färbung. 250:1.

Fig. 2. Querschnitt durch Corpus ciliare und angrenzende Sclera. Weigert'sche Färbung. $150: 1$.

a Sclera.

$b$ Blutgerinnsel.

c Blutiges Exsudat zwischen Sclera und Uvea.

d Corp. ciliare.

Dunkelgefärbte Nervenfasern im Corp. ciliare, Sclera und Perichorioidealraum. 

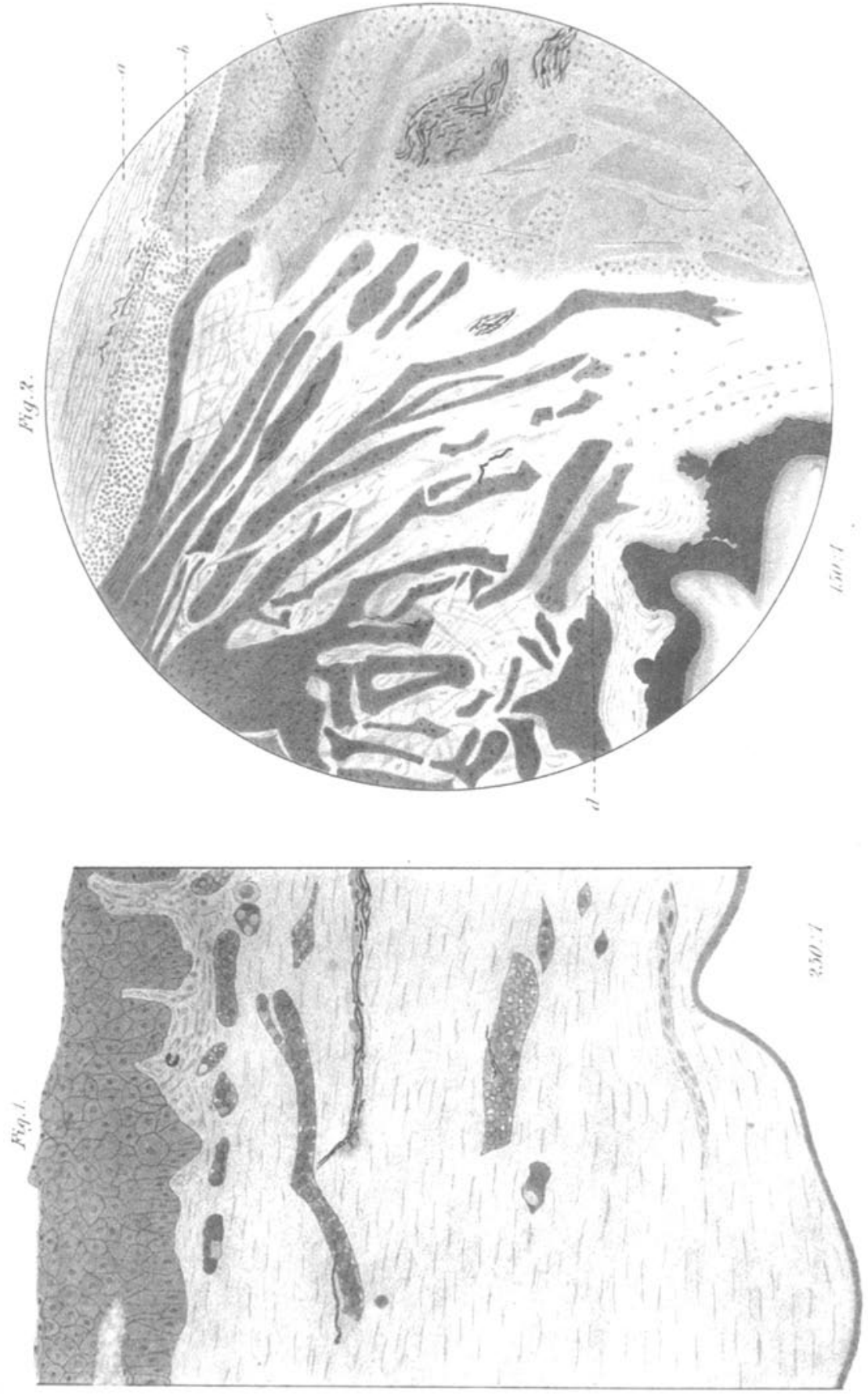